\title{
Solution to Ostwald's dilution law challenge
}

\author{
Anna M. Michałowska-Kaczmarczyk • Tadeusz Michałowski
}

(C) Springer-Verlag Berlin Heidelberg 2014

The winner of the Ostwald's dilution law challenge (published in volume 406 issue 12) is:

Claus Hansen, Department of Pharmacy, University of Copenhagen, Sweden

The award entitles the winner to select a Springer book of his choice up to a value of $€ 100$.

Our Congratulations!

\section{Solution}

The Ostwald's dilution law challenge [1] sought to rectify the erroneous conclusion that one might obtain from the popular expression of Ostwald's dilution law,

$K_{1}=\frac{C \cdot \alpha^{2}}{1-\alpha}$

One should take into account that Eq. (1) was obtained under the assumption that the equality $\left[\mathrm{H}^{+}\right]=\left[\mathrm{L}^{-}\right]$is valid. However, unlike the concentration of $\mathrm{L}^{-}$ions, the hydrogen-ion concentration is not zero at infinite dilutions. Rather,

$\lim _{C \rightarrow 0}\left[\mathrm{H}^{+}\right]=\sqrt{K_{\mathrm{W}}}$

In other words, infinitely diluted aqueous-acid solution is equivalent to pure water.

Combining the amount balance

$[\mathrm{HL}]+\left[\mathrm{L}^{-}\right]=C$

This article is the solution to the Analytical Challenge to be found at http://dx.doi.org/10.1007/s00216-014-7700-4

A. M. Michałowska-Kaczmarczyk

Department of Oncology, The University Hospital in Cracow,

31-501 Cracow, Poland

T. Michałowski $(\bowtie)$

Faculty of Engineering and Chemical Technology, Technical

University of Cracow, 31-155 Cracow, Poland

e-mail: michalot@o2.pl with the definitions of the dissociation constant $\left(K_{\mathrm{a}}\right)$ and degree of dissociation $(\alpha)$,

$K_{\mathrm{a}}=\frac{\left[\mathrm{H}^{+}\right]\left[\mathrm{L}^{-}\right]}{[\mathrm{HL}]}$

$\alpha=\frac{\left[\mathrm{L}^{-}\right]}{C}$

yields:

$\alpha=\frac{1}{1+\left[\mathrm{H}^{+}\right] / K_{\mathrm{a}}}$

From here, using (2), we obtain

$\alpha_{0}=\lim _{C \rightarrow 0} \alpha=\frac{1}{1+\sqrt{K_{\mathrm{w}}} / K_{\mathrm{a}}}=\frac{1}{1+10^{\mathrm{p} K_{\mathrm{a}}-\frac{1}{2} \mathrm{p} K_{\mathrm{w}}}}$

Putting $\mathrm{p} K_{\mathrm{w}}=14$ and $\mathrm{p} K_{\mathrm{a}}=4.75$ into (7), we obtain $\alpha_{0}=$ 0.994 for acetic acid. Thus, under infinite dilution, $0.6 \%$ of acetic acid remains undissociated. For cyanic acid, $\mathrm{HCN}$, with $\mathrm{p} K_{\mathrm{a}}=9.2$, we obtain $\alpha_{0}=0.00627$, i.e., $99.4 \%$ of $\mathrm{HCN}$ remains undissociated, under infinite dilution. These results contradict the simple inferences resulting from Eq. (1).

This column provides a detailed treatment of the problem associated with Ostwald's dilution law. In conclusion, it is suggested that the word "dilution" should be omitted from the name of this law. Ostwald's law, in the authors' opinion, has some applications for testing acid-base equilibria in aqueous and non-aqueous media. In particular, one can refer to the papers [2,3] devoted to formulation of $\mathrm{p} K_{\mathrm{a}}=\mathrm{p} K_{\mathrm{a}}\left(x_{\mathrm{B}}\right)$ relationships for some binary-solvent systems, where $x_{\mathrm{B}}$ is the amount fraction of co-solvent (B) in a mixture of solvents $(\mathrm{A}+\mathrm{B})$.

\section{References}

1. Michalowska-Kaczmarczyk AM, Michalowski T (2014) Anal Bioanal Chem 406:2741-2742

2. Pilarski B, Dobkowska A, Foks H, Michałowski T (2010) Talanta 80(3):1073-1080

3. Michałowski T, Pilarski B, Dobkowska A, Młodzianowski J (2010) Wiad Chem 54:124-154 